\title{
City Sustainable Development Evaluation Based on Hesitant Multiplicative Fuzzy Information
}

\author{
Xiaorong He and Yingyu Wu \\ School of Economics and Management, Southeast University, Nanjing 211189, China \\ Correspondence should be addressed to Xiaorong He; shelley526@126.com
}

Received 28 May 2017; Accepted 29 August 2017; Published 8 October 2017

Academic Editor: Fiorenzo A. Fazzolari

Copyright (c) 2017 Xiaorong He and Yingyu Wu. This is an open access article distributed under the Creative Commons Attribution License, which permits unrestricted use, distribution, and reproduction in any medium, provided the original work is properly cited.

\begin{abstract}
Sustainable development evaluation is the basis of city sustainable development research, and effective evaluation is the foundation for guiding the formulation and implementation of sustainable development strategy. In this paper, we provided a new city sustainable development evaluation method called hesitant multiplicative fuzzy TODIM (HMF-TODIM). The main advantage of this method is that it can deal with the subjective preference information of the decision-makers. The comparison study of existing methods and HMF-TODIM is also carried out. Additionally, real case analysis is presented to show the validity and superiority of the proposed method. Research results in this paper can provide useful information for the construction of sustainable cities.
\end{abstract}

\section{Introduction}

Urbanization brings a series of ecological and environmental problems while bringing about economic and social benefits [1]. For example, urbanization leads to water quality deterioration, resource depletion, air pollution, traffic congestion, and so on. The implementation of sustainable development is the only way for the development of urbanization and the urgent need of the international situation [2]. At present, the study on the evaluation of urban sustainable development is a universal issue [3]. At present, there are many researches on the evaluation of urban sustainable development at home and abroad. Most of the research has been carried out from the aspects of structure, coordination, and continuity of the cities [4]. In addition, most of the research has been using the traditional methods, such as AHP and Delphi. These methods cannot effectively deal with the subjective preferences of decision makers, and most models are difficult to apply to practice. This paper presents a new city sustainable development evaluation method based on hesitant multiplicative fuzzy information.

Since Zadeh proposed the theory of fuzzy set [5], it has been extended to intuitionistic fuzzy sets [6-11], hesitant fuzzy sets [12-15], dual hesitant fuzzy set [16-18], and so on. And the above extended fuzzy set has been used in decisionmaking problems [19-23]. Recently, Xia et al. [24] presented the concept of intuitionistic multiplicative preference relation (IMPR). Xia and Xu [25] proposed the hesitant multiplicative preference relation (HMPR). These two kinds of preference relation are very useful in describing the preference relations of the decision-makers [26-28].

As a useful tool for the multicriteria decision-making (MCDM) problem, the TODIM method was first introduced by Gomes and Lima $[29,30]$ and later widely spread in many fields for solving MCDM problems [31-33]. The TODIM method is based on the Prospect Theory [31] and takes the DMs' psychological information and emotional preference into consideration. At present, the TODIM method has been extended to intuitionistic fuzzy [34, 35], interval-valued intuitionistic fuzzy [36], and hesitant fuzzy environment [37]. However, the TODIM method has not been studied with HMPR which is the focus of this paper.

The remainder of this paper is organized as follows. In Section 2, the concepts about hesitant fuzzy preference relation and hesitant multiplicative preference relation are presented; the aggregation operations for hesitant multiplicative values are also provided. In Section 3, we present a distance measure for the hesitant multiplicative elements. Section 4 proposes an extended TODIM method under hesitant multiplicative environment. In Section 5, an illustrative example about city sustainable development evaluation is 
shown to demonstrate the feasibility of the proposed method. Concluding remarks are presented in Section 6.

\section{Preliminaries}

2.1. Hesitant Fuzzy Preference Relation and Hesitant Multiplicative Preference Relation. Inspired by the HFS (hesitant fuzzy set) [12] and FPR (fuzzy preference relation) [38], Liao et al. [39] presented a new concept called HFPR (hesitant fuzzy preference relation).

Definition 1 (see [39]). In a HFPR, we have a set of fixed alternatives $A=\left(A_{1}, A_{2}, \ldots, A_{n}\right)$ and then derive a matrix $B=\left(h_{i j}\right)_{n \times n} \in A \times A$, where $h_{i j}=\left\{h_{i j}^{l} \mid l=1,2, \ldots, l_{h_{i j}}\right\}$, through comparing every alternative with each other. And each $h_{i j}$ is expressed with several hesitant fuzzy values so that DMs can provide their preferences for alternative $h_{i}$ over alternative $h_{j}$ in a hesitancy range. What is more, each $h_{i j}$ should satisfy the following conditions:

$$
\begin{aligned}
h_{i j}^{\sigma(l)}+h_{j i}^{\left(l_{h_{i j}}-l+1\right)} & =1, \\
h_{i i} & =\{0.5\}, \\
l_{h_{i j}} & =l_{h_{j i}},
\end{aligned}
$$

where $h_{i j}=0.5$ means there is no difference between alternative $i$ and alternative $j, h_{i j}<0.5$ means the alternative $i$ is superior to alternative $j$, and the $h_{i j}>0.5$ means the alternative $j$ is superior to alternative $i$.

Based on the proposal of HFPR, an extended concept called HMPR (hesitant multiplicative preference relation), which utilizes a new information expressing method, is presented by Xia and Xu [25]. The only difference between the two concepts is that the HMPR uses Saaty's 1-9 scale while the HFPR uses the 0.1-0.9 scale. Firstly, we give the definitions of HMS (hesitant multiplicative set) and HME (hesitant multiplicative element) proposed by Zhang and $\mathrm{Wu}$ [40]. Then we introduce the concept of HMPR.

Definition 2 (see [40]). A HMS $C$ on a fixed set $X$ is defined as follows:

$$
C=\left\{\left\langle x, h_{C}(x)\right\rangle \mid x \in X\right\}
$$

$h_{C}(x)$ is a HME of $x \in X$ and $h_{C}(x)$ satisfies the following conditions:

$$
\begin{aligned}
& \frac{1}{9} \leq \xi \leq 9, \\
& \forall x \in X, \\
& \forall \xi \in h_{C}(x) .
\end{aligned}
$$

Definition 3 (see [25]). In a HMPR, we have a set of fixed alternatives $\widetilde{A}=\left(\widetilde{A_{1}}, \widetilde{A_{2}}, \ldots, \widetilde{A_{n}}\right)$ and then derive a matrix $\widetilde{B}=\left(\widetilde{h_{i j}}\right)_{n \times n} \in \widetilde{A} \times \widetilde{A}$, where $\widetilde{h_{i j}}=\left\{\widetilde{h_{i j}^{l}} \mid l=1,2, \ldots, \widetilde{l_{h_{i j}}}\right\}$, through comparing alternative $i$ with alternative $j$. And each $\widetilde{h_{i j}}$ should satisfy the following conditions:

$$
\begin{aligned}
& \widetilde{h_{i j}^{\sigma(l)}} h_{j i}^{\left(l_{h_{i j}}-l+1\right)}=1, \\
& \widetilde{h_{i i}}=\{1\}, \\
& l_{\widetilde{h_{i j}}}=l_{\widetilde{h_{j i}}} \text {. }
\end{aligned}
$$

We define that $\widetilde{h_{i j}}$ is a HME where $\widetilde{h_{i j}} \in[1 / 9,9]$ and $\widetilde{h_{i j}}=$ 1 means the alternative $i$ is equally preferred to alternative $j ; 1 / 9 \leq \widetilde{h_{i j}}<1$ means the alternative $i$ is not preferred to alternative $j$; and $1<\widetilde{h_{i j}} \leq 9$ means the alternative $i$ is preferred to alternative $j$. What is more, $\widetilde{h_{i j}}=\{1 / 9\}$ presents the alternative $i$ is extremely not preferred to alternative $j$ and contrarily $\widetilde{h_{i j}}=\{9\}$ presents the alternative $i$ is extremely preferred to alternative $j$.

2.2. Aggregation Operations for Hesitant Multiplicative Values. Aggregation operator is an important research topic in decision-making problems [41-44]. Hesitant multiplicative information aggregation operators were first proposed by $\mathrm{Xia}$ and $\mathrm{Xu}$ [25]. Then Yu [45] made some changes and presented some extended aggregation operators. In this paper, we use the following operator [45] to aggregate hesitant multiplicative information. The operator is stated as follows:

$$
\operatorname{HMFWA}\left(\rho_{1}, \rho_{2}, \ldots, \rho_{n}\right)=w_{1} \rho_{1} \oplus w_{2} \rho_{2} \oplus \cdots \oplus w_{n} \rho_{n} .
$$

This operator is called HMFWA (hesitant multiplicative fuzzy weighted averaging) operator and $\rho=\left(\rho_{1}, \rho_{2}, \ldots, \rho_{n}\right)$ is a set of HMNs (hesitant multiplicative numbers). After that, $\mathrm{Yu}$ [45] presented a theorem with a condition that $w=$ $\left(w_{1}, w_{2}, \ldots, w_{n}\right)$ is a set of weight vectors with respect to the HMNs $\rho=\left(\rho_{1}, \rho_{2}, \ldots, \rho_{n}\right)$, where $w_{i} \in[0,1]$ and $\sum_{i=1}^{n} w_{i}=1$. And $\eta_{i}$ is the value in the $\operatorname{HMN} \rho_{i}$. The theorem is provided below:

$$
\begin{aligned}
& \operatorname{HMFWA}\left(\rho_{1}, \rho_{2}, \ldots, \rho_{n}\right) \\
& =\bigcup_{\eta_{i} \in \rho_{i}}\left\{\frac{\prod_{i=1}^{n}\left(1+2 \eta_{i}\right)^{w_{i}}-1}{2}\right\} .
\end{aligned}
$$

\section{Distance Measure for HMEs}

In this section, we propose a new distance measure for integrating the HMEs in order to combine with the TODIM method. We would set a nonideal HME and derive a series of corresponding values through calculating the distance between the nonideal HME and each HME we picked. According to the definition of the distance measure, the higher the score is, the bigger the difference between two objects is. What is more, the bigger the difference between the ideal HME and the HME we picked is, the better the $\mathrm{HME}$ is. So we can realize the target of evaluating each HME via the distance measure and the effect of it. And the effect is similar to the compatibility degree between a pair 
of intuitionistic multiplicative values presented by Jiang et al. [46]. We concisely represent the distance measure presented by $\mathrm{Xu}$ and Xia [47], called hesitant normalized Hamming distance.

$$
d_{h n h}(M, N)=\frac{1}{n} \sum_{i=1}^{n}\left[\frac{1}{l_{x_{i}}} \sum_{j=1}^{l_{x_{i}}}\left|h_{M}^{\sigma(j)}\left(x_{i}\right)-h_{N}^{\sigma(j)}\left(x_{i}\right)\right|\right] .
$$

We need to calculate the distance between HMEs; however, this distance measure is for HFSs. In order to fit our method, we made a little change to this distance measure. And then we can calculate the distance between HMEs and present the measure as follows:

$$
d\left(h_{1}, h_{2}\right)=\frac{1}{l_{x}} \sum_{j=1}^{l_{x}}\left|h_{1}^{\sigma(j)}(x)-h_{2}^{\sigma(j)}(x)\right|
$$

where $h_{1}$ and $h_{2}$ are two HMEs. All the values in each HME are in a monotone increasing order and $\sigma(j)$ is the $j$ th largest value in the element. What is more, $l_{x}$ represents the number of the values in the HME.

HMEs and HFEs have many similar characteristics. For instance, they both have a membership degree containing several possible valves to express DMs' preferences under hesitancy and uncertainty. The only difference is that HMEs are denoted by Saaty's 1-9 scale so the distance measure is also applicable to the calculation under hesitant multiplicative fuzzy environment.

\section{Extended TODIM Method under Hesitant Multiplicative Environment}

4.1. The Classical TODIM Method. Suppose there is a MCDM problem $[19,48-64]$; the set of alternatives were represented as $A=\left(A_{1}, A_{2}, \ldots, A_{m}\right)$ as well as a set of criteria as shown as $C=\left(C_{1}, C_{2}, \ldots, C_{n}\right)$. Assume one of the criteria as the reference criterion and give the weight vectors denoted as $w=\left(w_{1}, w_{2}, \ldots, w_{n}\right)$ with respect to the set of criteria and the weight vectors satisfy $w_{i} \in[0,1]$ and $\sum_{i=1}^{n} w_{i}=1$. Then experts are asked to estimate each alternative. After obtaining the values of the alternatives, each value should be divided by the sum of all the values and then obtain a matrix where the values are normalized [65-73]. The matrix of the values is called the normalized alternatives' scores against criteria and the matrix is denoted as $A=\left[a_{m n}\right]$ in Table 1 .

After assigning the proper values to the weights and its normalization, DMs have to select a reference criterion $w_{r}$ which is the most vital compared with the other criteria. $w_{r c}=w_{c} / w_{r}, w_{c}$ is the weight of criterion $c$.

Each alternative's performance should be transformed into the same dimension via using $w_{r c}$. And we use the following mathematical expression to calculate the dominance of alternative $a_{i}$ over another alternative $a_{j}$.

$$
\delta\left(a_{i}, a_{j}\right)=\sum_{c=1}^{m} \Phi_{c}\left(a_{i}, a_{j}\right), \quad \forall(i, j)
$$

TABLE 1: Normalized alternatives' scores against criteria.

\begin{tabular}{lcccc}
\hline & $C_{1}$ & $C_{2}$ & $\cdots$ & $C_{n}$ \\
\hline$A_{1}$ & $a_{11}$ & $a_{12}$ & $\cdots$ & $a_{1 n}$ \\
$A_{2}$ & $a_{21}$ & $a_{22}$ & $\cdots$ & $a_{2 n}$ \\
$\vdots$ & $\vdots$ & $\vdots$ & $\ddots$ & $\vdots$ \\
$A_{m}$ & $a_{m 1}$ & $a_{m 2}$ & $\cdots$ & $a_{m n}$ \\
\hline
\end{tabular}

when

$$
\begin{aligned}
& \Phi_{c}\left(a_{i}, a_{j}\right) \\
& \quad= \begin{cases}\sqrt{\frac{w_{r c}\left(a_{i c}-a_{j c}\right)}{\sum_{c=1}^{m} w_{r c}}} & a_{i c}-a_{j c}>0 \\
0 & a_{i c}-a_{j c}=0 \\
\frac{-1}{\theta} \sqrt{\frac{\left(\sum_{c=1}^{m} w_{r c}\right)\left(a_{j c}-a_{i c}\right)}{w_{r c}}} & a_{i c}-a_{j c}<0 .\end{cases}
\end{aligned}
$$

$\theta$ is a parameter of the attenuation factor of the losses.

Then we need to calculate the global value of alternative $a_{i}$ using the following expression:

$$
\xi_{i}=\frac{\sum_{j=1}^{n} \delta\left(a_{i}, a_{j}\right)-\min _{i} \sum_{j=1}^{n} \delta\left(a_{i}, a_{j}\right)}{\max _{i} \sum_{j=1}^{n} \delta\left(a_{i}, a_{j}\right)-\min _{i} \sum_{j=1}^{n} \delta\left(a_{i}, a_{j}\right)} .
$$

Finally, we can rank the alternatives varying from 1 to $m$ according to the global value, respectively.

4.2. An Extended TODIM Method. We plan to present a new TODIM method synthesizing the aggregation operations, distance measures, and classical TODIM method mentioned above. Our innovation is to utilize the TODIM method's advantages such as considering the DMs' psychological information and emotional preference, to solve MCDM problems under hesitant multiplicative environment. Zhang and $\mathrm{Wu}$ [40] had solved a MCMD problem using some aggregation operations with interval-valued hesitant information. Nevertheless, they only relied on aggregation operations to deal with the alternatives' performances but not thinking about something psychological. So our method is necessary and valid for this black space.

Step 1. We provide a set of alternatives denoted as $A=$ $\left(A_{1}, A_{2}, \ldots, A_{m}\right)$ and several criteria $C=\left(C_{1}, C_{2}, \ldots, C_{n}\right)$. Besides we set weight vectors $w=\left(w_{1}, w_{2}, \ldots, w_{n}\right)$ for the criteria with $w_{i} \in[0,1]$ and $\sum_{i=1}^{n} w_{i}=1$. What is more, we need a group of experts $E=\left(e_{1}, e_{2}, \ldots, e_{k}\right)$ to give their evaluation using hesitant multiplicative information. According to these, we obtain a HMPR called $B=\left(b_{i j}\right)_{m \times m}$ constructed by 
TABLE 2: The distance values between alternatives and the nonideal alternative.

\begin{tabular}{lcccc}
\hline & $C_{1}$ & $C_{2}$ & $\cdots$ & $C_{n}$ \\
\hline$A_{1}$ & $d_{1}^{(1)}$ & $d_{1}^{(2)}$ & $\cdots$ & $d_{1}^{(n)}$ \\
$A_{2}$ & $d_{2}^{(1)}$ & $d_{2}^{(2)}$ & $\ldots$ & $d_{2}^{(n)}$ \\
$\vdots$ & $\vdots$ & $\vdots$ & $\ddots$ & $\vdots$ \\
$A_{m}$ & $d_{m}^{(1)}$ & $d_{m}^{(2)}$ & $\ldots$ & $d_{m}^{(n)}$ \\
\hline
\end{tabular}

Saaty's 1-9 scale, where $b_{i j}$ represents the dominance degree of alternative $i$ over alternative $j$. Compared with the ordinary HMPR, there is a little difference in the following step which we use a set of criteria to replace the role of decision organization. In general, we obtain some HMPRs associated with each decision organization, respectively. However, in order to accomplish the new method combined with the TODIM method, we need experts to provide their preferences for each alternative with respect to the criteria. Furthermore due to the restriction of professions, experts are not permitted to evaluate certain alternative associated with a criterion if they know little about it. Note that experts are independent of each other. Then we can obtain a hesitant multiplicative preference relation called $R_{n}=\left(r_{i j}{ }^{(n)}\right)_{n \times n}$, where $r_{i j}{ }^{(n)}$ denotes all the values given by experts comparing alternative $i$ with alternative $j$ with respect to the criterion $n$.

Step 2. We use (6) to aggregate every $r_{i j}{ }^{(n)}(j=1,2, \ldots, m)$ in the HMPR associated with each criterion, respectively, and then derive a series of $r_{i}^{(n)}$ for the alternative $i$ under the criterion $n$.

Step 3. Set a nonideal element with the minimum hesitant multiplicative value (HMV) called $A^{*}$, where $A^{*}=\{1 / 9\}$. Then we calculate the distance between the nonideal alternative and the target element $r_{i}^{(n)}$ we calculated in the last step, via utilizing (8). It is obvious that the bigger the distance value is, the better the performance of the alternative is. According to this, we can obtain a new matrix called $D=\left(d_{i}^{(n)}\right)_{n \times n}$ composed of the distance grades $d_{i}^{(n)}$ between the nonideal element and each alternative $i$ associated with the criterion $n$, respectively. And this matrix was presented in Table 2.

In Table $2, A=\left(A_{1}, A_{2}, \ldots, A_{m}\right)$ and $C=$ $\left(C_{1}, C_{2}, \ldots, C_{n}\right)$ indicate the alternatives and criteria we selected, respectively.

Step 4. We utilize the TODIM method to deal with the matrix $D=\left(d_{i}^{(n)}\right)_{n \times n}$. Through the process, we can obtain the global values of the alternatives and get the rank ordering for these alternatives. Specific processes are as follows:

(i) Calculate the dominance of alternative $d_{i}^{(n)}$ over another alternative $d_{j}^{(n)}$ corresponding to each criterion after determining the reference criterion $w_{r}$, via the expression

$$
\delta\left(d_{i}, d_{j}\right)=\sum_{c=1}^{m} \Phi_{c}\left(d_{i}, d_{j}\right), \quad \forall(i, j)
$$

TABLE 3: The hesitant multiplicative preference relation $R_{1}$.

\begin{tabular}{cccc}
\hline & $x_{1}$ & $x_{2}$ & $x_{3}$ \\
\hline$x_{1}$ & $\{1\}$ & $\{3 / 2,2\}$ & $\{2,3,4\}$ \\
$x_{2}$ & $\{1 / 2,2 / 3\}$ & $\{1\}$ & $\{3,4\}$ \\
$x_{3}$ & $\{1 / 4,1 / 3,1 / 2\}$ & $\{1 / 4,1 / 3\}$ & $\{1\}$ \\
\hline
\end{tabular}

TABLE 4: The hesitant multiplicative preference relation $R_{2}$.

\begin{tabular}{cccc}
\hline & $x_{1}$ & $x_{2}$ & $x_{3}$ \\
\hline$x_{1}$ & $\{1\}$ & $\{3 / 2,3 / 4,5 / 6\}$ & $\{3 / 2,2,3\}$ \\
$x_{2}$ & $\{6 / 5,4 / 3,2\}$ & $\{1\}$ & $\{1 / 5,1 / 3,1 / 2\}$ \\
$x_{3}$ & $\{1 / 3,1 / 2,2 / 3\}$ & $\{2,3,5\}$ & $\{1\}$ \\
\hline
\end{tabular}

when

$$
\begin{aligned}
& \Phi_{c}\left(d_{i}, d_{j}\right) \\
& = \begin{cases}\sqrt{\frac{w_{r c}\left(d_{i}^{(n)}-d_{j}^{(n)}\right)}{\sum_{c=1}^{m} w_{r c}}} & d_{i}^{(n)}-d_{j}^{(n)}>0 \\
0 & d_{i}^{(n)}-d_{j}^{(n)}=0 \\
\frac{-1}{\theta} \sqrt{\frac{\left(\sum_{c=1}^{m} w_{r c}\right)\left(d_{j}^{(n)}-d_{i}^{(n)}\right)}{w_{r c}}} & d_{i}^{(n)}-d_{j}^{(n)}<0 .\end{cases}
\end{aligned}
$$

$\theta$ is a parameter to reflect the attenuation of the losses.

(ii) Calculate the global values of each alternative using the following formula:

$$
\xi_{i}=\frac{\sum_{j=1}^{n} \delta\left(d_{i}, d_{j}\right)-\min _{i} \sum_{j=1}^{n} \delta\left(d_{i}, d_{j}\right)}{\max _{i} \sum_{j=1}^{n} \delta\left(d_{i}, d_{j}\right)-\min _{i} \sum_{j=1}^{n} \delta\left(d_{i}, d_{j}\right)} .
$$

\section{Case Studies}

Sustainable development evaluation is the basis of urban sustainable development research, and correct evaluation is an important basis for guiding the formulation and implementation of sustainable development strategy. At the same time, due to the specificity and complexity of the city, the sustainable development of different cities is difficult to use the same indicators. Therefore, the sustainable development evaluation is both a hot and difficult point in the field of research.

Starting from the three aspects of economy $\left(c_{1}\right)$, society $\left(c_{2}\right)$, and resources and environment $\left(c_{3}\right)$, the sustainable development level and ability of three cities $X=\left(x_{1}, x_{2}, x_{3}\right)$ in Zhejiang province, China, are evaluated.

We invite three experts $E=\left(e_{1}, e_{2}, e_{3}\right)$ to give their assessment with respective to the three cities associated with different criteria. What is more, each expert is not disturbed by each other.

First we obtain three matrices denoted by the HMPR for each criterion called $R=\left(R_{1}, R_{2}, R_{3}\right)$. The matrices $R_{1}, R_{2}, R_{3}$ are the HMPRs associated with the three cities under $c_{1}$ (economy), $c_{2}$ (society), and $c_{3}$ (resources and environment), respectively. The values in the HMPRs are the primary data provided by the experts and we present them in Tables 3-5. 
TABLE 5: The hesitant multiplicative preference relation $R_{3}$.

\begin{tabular}{cccc}
\hline & $x_{1}$ & $x_{2}$ & $x_{3}$ \\
\hline$x_{1}$ & $\{1\}$ & $\{2,3\}$ & $\{6,7,8\}$ \\
$x_{2}$ & $\{1 / 3,1 / 2\}$ & $\{1\}$ & $\{2,3,4\}$ \\
$x_{3}$ & $\{1 / 8,1 / 7,1 / 6\}$ & $\{1 / 4,1 / 3,1 / 2\}$ & $\{1\}$ \\
\hline
\end{tabular}

TABLE 6: The distance values between the three companies and the nonideal alternative.

\begin{tabular}{cccc}
\hline & $x_{1}$ & $x_{2}$ & $x_{3}$ \\
\hline$x_{1}$ & 1.6490 & 1.1971 & 2.6062 \\
$x_{2}$ & 1.2507 & 0.7470 & 1.0651 \\
$x_{3}$ & 0.3944 & 1.5596 & 0.3282 \\
\hline
\end{tabular}

TABLE 7: The dominance degrees of the three companies over each other.

\begin{tabular}{cccc}
\hline & $x_{1}$ & $x_{2}$ & $x_{3}$ \\
\hline$x_{1}$ & 1 & 1.3689 & 1.5781 \\
$x_{2}$ & -4.8933 & 1 & -0.1293 \\
$x_{3}$ & -5.3293 & -2.8779 & 1 \\
\hline
\end{tabular}

(i) Then we use the aggregation operations to deal with the primary data via (6) and derive nine results of each alternative with respect to the criteria denoted as $r_{i}^{(n)}$, where $i$ means the alternative $i$ and $n$ means the criterion $n$.

$$
\begin{aligned}
& r_{1}^{(1)}=\{1.4574,1.6897,1.8811,1.6086,1.8588,2.0650\} \\
& r_{2}^{(1)}=\{1.2380,1.3899,1.3297,1.4895\} \\
& r_{3}^{(1)}=\{0.4449,0.4787,0.4787,0.5317,0.5400,0.5772\}, \\
& r_{1}^{(2)}=\{1.3333,1.4574,1.6898,1.0536,1.1736,1.3722,1.0874,1.2100,1.4129\} \\
& r_{2}^{(2)}=\{0.7131,0.7856,0.8662,0.7440,0.8184,0.9010,0.8795,0.9620,1.0536\} \\
& r_{3}^{(2)}=\{0.9620,1.1356,1.4015,1.0536,1.2380,1.5206,1.1355,1.3297,1.6272\} \\
& r_{1}^{(3)}=\{2.3994,2.5411,2.6707,2.7436,2.99020,3.0470\}, \\
& r_{2}^{(3)}=\{0.9620,1.1355,1.2784,1.0536,1.2380,1.3900\}, \\
& r_{3}^{(3)}=\{0.3892,0.4210,0.4787,0.3976,0.4297,0.4880,0.4086,0.4410,0.500\}
\end{aligned}
$$

(ii) In general cases of group decision-making (GDM) problem, lots of researchers use a weighted aggregation operation to aggregate $r_{i}^{(n)}$ and obtain $r_{i}$ which means the global value of alternative $i$ over the other alternatives. Even Zhang and $\mathrm{Wu}$ [40] did the same work in a MCMD problem based on the interval-valued hesitant multiplicative preference relation. However we do not use this operation but lead a distance measure (8) into this step to calculate the distance between the alternatives we picked and a nonideal alternative $A^{*}=\{1 / 9\}$. So we can illustrate whether an alternative's value is bigger than another one through calculating their distance value $d_{i}^{(n)}$. And we obtain a matrix $D=\left\{d_{i}^{(n)}\right\}_{n \times n}$ composed of the distance values in Table 6.

(iii) The distance values of $x_{1}$ are bigger than those of $x_{2}$ and $x_{3}$ associated with $c_{1}$ and $c_{3}$. And the distance value of $x_{3}$ associated with $c_{2}$ ranks first. As we mentioned in Section 4.2, the bigger the distance value is, the better the alternative's performance is. Therefore the result we obtained in Table 7 means the performance of $x_{1}$ associated with $c_{1}$ and $c_{3}$ is best, while the performance of $x_{3}$ related to $c_{2}$ is better than the other two.

(iv) We use the TODIM method to deal with the matrix calculated above and gain the dominance degree of each alternative via (12). We present the dominance degree in Table 7. And then we can get the global valves of all the alternatives which are presented in Table 8.

From the result, it is obvious that $x_{1}$ is ranked first. We can roughly derive that $x_{1}$ possesses the biggest distance value with the nonideal alternative compared with the other two in Table 7. As we mentioned above, the bigger the distance value is, the better the alternative's performance is. Therefore, after calculating the distance values between the three companies and the nonideal alternative, the dominant position of $x_{1}$ is relatively manifest. And in Table 7, the superiority of $x_{1}$ is more obvious because only the dominance degree of $x_{1}$ is a positive number while the dominance degrees of the other two are negative numbers. And the definition of the dominance degree is the comparison of two alternatives' advantages and disadvantages. Therefore we can infer that $x_{1}$ is the best from the result of calculating the dominance degree.

5.1. Comparison between the New Method and an Aggregation Operation Method. In this subsection, we plan to do a comparison between our new method, HMF-TODIM, and an existing method based on aggregation operations proposed by $\mathrm{Yu}[45]$ which is provided as follows. 
TABLE 8: The global values of the three companies and their rank ordering.

\begin{tabular}{lcc}
\hline & Global value & Rank \\
\hline$x_{1}$ & 1 & 1 \\
$x_{2}$ & 0.2855 & 2 \\
$x_{3}$ & 0 & 3 \\
\hline
\end{tabular}

TABLE 9: The score values and the rank ordering concerning the three alternatives.

\begin{tabular}{lcc}
\hline & Score value & Rank \\
\hline$x_{1}$ & 1.7822 & 1 \\
$x_{2}$ & 1.1136 & 2 \\
$x_{3}$ & 0.6681 & 3 \\
\hline
\end{tabular}

Step 1. Use (6) to aggregate every $r_{i j}{ }^{(n)}(j=1,2, \ldots, m)$ in the HMPRs associated with each criterion in Tables 3-5, respectively. And then derive a series of $r_{i}^{(n)}$ for the alternative $i$ under the criterion $n$. This step is the same as the HMFTODIM method.

Step 2. Through utilizing (6) again, we aggregate each $r_{i}^{(n)}$ to derive every alternative's global value $r_{i}$. The global value indicates the performance of each alternative related to the all criteria under the hesitant multiplicative environment.

Step 3. According to a score function defined by Xia [74], identify the sorting of the alternatives' values. And the score function is given as follows:

$$
s(r)=\sqrt[1 / 4]{\prod_{\eta \in h} \eta} .
$$

Noting that $\Delta h$ is the number of the values of $r$, if $s\left(r_{1}\right)>$ $s\left(r_{2}\right)$, then $r_{1}>r_{2}$.

It is obvious to see that Step 1 of this method is the same as Step 2 of the HMF-TODIM method. Therefore we can obtain the same values to the set of $r_{i}^{(n)}$ :

$$
\begin{aligned}
& r_{1}^{(1)}=\{1.4574,1.6897,1.8811,1.6086,1.8588,2.0650\}, \\
& r_{2}^{(1)}=\{1.2380,1.3899,1.3297,1.4895\} \\
& r_{3}^{(1)}=\{0.4449,0.4787,0.4787,0.5317,0.5400,0.5772\}, \\
& r_{1}^{(2)}=\{1.3333,1.4574,1.6898,1.0536,1.1736,1.3722,1.0874,1.2100,1.4129\} \\
& r_{2}^{(2)}=\{0.7131,0.7856,0.8662,0.7440,0.8184,0.9010,0.8795,0.9620,1.0536\} \\
& r_{3}^{(2)}=\{0.9620,1.1356,1.4015,1.0536,1.2380,1.5206,1.1355,1.3297,1.6272\} \\
& r_{1}^{(3)}=\{2.3994,2.5411,2.6707,2.7436,2.99020,3.0470\}, \\
& r_{2}^{(3)}=\{0.9620,1.1355,1.2784,1.0536,1.2380,1.3900\}, \\
& r_{3}^{(3)}=\{0.3892,0.4210,0.4787,0.3976,0.4297,0.4880,0.4086,0.4410,0.500\}
\end{aligned}
$$

Then we aggregate the set of $r_{i}^{(n)}$ to obtain the global values $r_{i}$ via (6). Considering the enormous calculation process, we do not put the calculation result of Step 2 in our paper.

Finally, we identify the sorting of the three alternatives via the score function.

$s\left(r_{1}\right)=1.7822, s\left(r_{2}\right)=1.1136$, and $s\left(r_{3}\right)=0.6681$. Since $s\left(r_{1}\right)>s\left(r_{2}\right)>s\left(r_{3}\right)$, then $r_{1}>r_{2}>r_{3}$, and we present the score values related to the alternatives in Table 9.

\section{Conclusion}

In this paper, we proposed a new TODIM method called HMF-TODIM method and applied it to the field of city sustainable development evaluation. The use of asymmetric information can solve more practical problems in the real world. Expressing the DMs' preferences with asymmetric information is more scientific and closer to the reality because the DMs' preference degrees may increase irregularly. For instance, the growth range from the extremely nonpreferred one to the equally preferred one may be smaller than that from the extremely preferred one to the equally preferred one. In addition, we also considered the hesitancy and uncertainty during decision-making process. A real case analysis is presented to show the validity and superiority of the proposed method. In the future study, we intend to apply the proposed methods to the field of energy [75-78] and supplier evaluation and selection [79-81].

\section{Conflicts of Interest}

The authors declare that there are no conflicts of interest regarding the publication of this article. 


\section{Acknowledgments}

The authors wish to thank Miss Shi Shunshun from Zhejiang University of Finance and Economics for the assistance and useful advice.

\section{References}

[1] L. Liu, Y. Lin, L. Wang et al., "An integrated local climatic evaluation system for green sustainable eco-city construction: a case study in Shenzhen, China," Building and Environment, vol. 114, pp. 82-95, 2017.

[2] H. Haghshenas, M. Vaziri, and A. Gholamialam, "Evaluation of sustainable policy in urban transportation using system dynamics and world cities data: a case study in Isfahan," Cities, vol. 45, pp. 104-115, 2015.

[3] B. Pu and Y. Qiu, "The synergy between city human resources and city economy development based on the city marketing: the case of Chengdu," Mathematical Problems in Engineering, vol. 2014, Article ID 892526, 9 pages, 2014.

[4] J. Yu, S. Yao, R. Chen, K. Zhu, and L. Yu, "A quantitative integrated evaluation of sustainable development of mineral resources of a mining city: a case study of Huangshi, Eastern China," Resources Policy, vol. 30, no. 1, pp. 7-19, 2005.

[5] L. A. Zadeh, "Fuzzy sets," Information and Control, vol. 8, no. 3, pp. 338-353, 1965.

[6] K. T. Atanassov, "Intuitionistic fuzzy sets," Fuzzy Sets and Systems, vol. 20, no. 1, pp. 87-96, 1986.

[7] W. Zhou and J.-M. He, "Intuitionistic fuzzy geometric bonferroni means and their application in multicriteria decision making," International Journal of Intelligent Systems, vol. 27, no. 12, pp. 995-1019, 2012.

[8] D. Yu, "Multi-criteria decision making based on generalized prioritized aggregation operators under intuitionistic fuzzy environment," International Journal of Fuzzy Systems, vol. 15, no. 1, pp. 47-54, 2013.

[9] D. Yu, "Intuitionistic fuzzy theory based typhoon disaster evaluation in Zhejiang Province, China: a comparative perspective," Natural Hazards, vol. 75, no. 3, pp. 2559-2576, 2014.

[10] X. He, Y. Wu, and D. Yu, "Intuitionistic fuzzy multi-criteria decision making with application to job hunting: a comparative perspective," Journal of Intelligent and Fuzzy Systems, vol. 30, no. 4, pp. 1935-1946, 2016.

[11] D. J. Yu and L. Fang, "Intuitionistic multiplicative aggregation operators with their application in group decision making," Journal of Intelligent and Fuzzy Systems, vol. 27, no. 1, pp. 131142, 2014.

[12] V. Torra, "Hesitant fuzzy sets," International Journal of Intelligent Systems, vol. 25, no. 6, pp. 529-539, 2010.

[13] W. Zhou and Z. Xu, "Asymmetric hesitant fuzzy sigmoid preference relations in the analytic hierarchy process," Information Sciences, vol. 358-359, pp. 191-207, 2016.

[14] W. Zhou and Z. Xu, "Expected hesitant VaR for tail decision making under probabilistic hesitant fuzzy environment," Applied Soft Computing, vol. 60, pp. 297-311, 2017.

[15] D. J. Yu, "Hesitant fuzzy multi-criteria decision making methods based on Heronian mean," Technological and Economic Development of Economy, vol. 23, no. 2, pp. 296-315, 2017.

[16] B. Zhu, Z. Xu, and M. Xia, "Dual hesitant fuzzy sets," Journal of Applied Mathematics, vol. 2012, Article ID 879629, 13 pages, 2012.
[17] D. Yu, W. Zhang, and G. Huang, "Dual hesitant fuzzy aggregation operators," Technological and Economic Development of Economy, vol. 22, no. 2, pp. 194-209, 2016.

[18] D. Yu, D.-F. Li, and J. M. Merigó, "Dual hesitant fuzzy group decision making method and its application to supplier selection," International Journal of Machine Learning and Cybernetics, vol. 7, no. 5, pp. 819-831, 2016.

[19] W. Zhou and Z. Xu, "Generalized asymmetric linguistic term set and its application to qualitative decision making involving risk appetites," European Journal of Operational Research, vol. 254, no. 2, pp. 610-621, 2016.

[20] D.-F. Li, "Multiattribute decision making models and methods using intuitionistic fuzzy sets," Journal of Computer and System Sciences, vol. 70, no. 1, pp. 73-85, 2005.

[21] D. Yu, D.-F. Li, J. M. Merigó, and L. Fang, "Mapping development of linguistic decision making studies," Journal of Intelligent and Fuzzy Systems, vol. 30, no. 5, pp. 2727-2736, 2016.

[22] D. Yu, "Decision making based on generalized geometric operator under interval-valued intuitionistic fuzzy environment," Journal of Intelligent \& Fuzzy Systems, vol. 25, no. 2, pp. 471-480, 2013.

[23] D. Yu, Y. Wu, and T. Lu, "Interval-valued intuitionistic fuzzy prioritized operators and their application in group decision making," Knowledge-Based Systems, vol. 30, pp. 57-66, 2012.

[24] M. Xia, Z. Xu, and H. Liao, "Preference relations based on intuitionistic multiplicative information," IEEE Transactions on Fuzzy Systems, vol. 21, no. 1, pp. 113-133, 2013.

[25] M. Xia and Z. Xu, "Managing hesitant information in GDM problems under fuzzy and multiplicative preference relations ," International Journal of Uncertainty, Fuzziness and KnowledgeBased Systems, vol. 21, no. 6, pp. 865-897, 2013.

[26] B. Zhu and Z. Xu, "Consistency measures for hesitant fuzzy linguistic preference relations," IEEE Transactions on Fuzzy Systems, vol. 22, no. 1, pp. 35-45, 2014.

[27] H. Wang and Z. Xu, "Some consistency measures of extended hesitant fuzzy linguistic preference relations," Information Sciences, vol. 297, pp. 316-331, 2015.

[28] D. Yu, "Group decision making under interval-valued multiplicative intuitionistic fuzzy environment based on archimedean t-conorm and t-norm," International Journal of Intelligent Systems, vol. 30, no. 5, pp. 590-616, 2015.

[29] L. F. A. M. Gomes and M. M. P. P. Lima, "TODIM: basics and application to multicriteria ranking of projects with environmental impacts," Foundations of Computing and Decision Sciences, vol. 16, no. 4, pp. 113-127, 1991.

[30] L. F. A. M. Gomes and M. M. P. P. Lima, "From modeling individual preferences to multicriteria ranking of discrete alternatives: a look at prospect theory and the additive difference model," Foundations of Computing and Decision Sciences, vol. 17, no. 3, pp. 171-184, 1992.

[31] L. F. A. M. Gomes and L. A. D. Rangel, "An application of the TODIM method to the multicriteria rental evaluation of residential properties," European Journal of Operational Research, vol. 193, no. 1, pp. 204-211, 2009.

[32] J. Qin, X. Liu, and W. Pedrycz, "An extended TODIM multicriteria group decision making method for green supplier selection in interval type-2 fuzzy environment," European Journal of Operational Research, vol. 258, no. 2, pp. 626-638, 2017.

[33] C. Tan, Z.-Z. Jiang, and X. Chen, "An extended TODIM method for hesitant fuzzy interactive multicriteria decision making based on generalized Choquet integral," Journal of Intelligent and Fuzzy Systems, vol. 29, no. 1, pp. 293-305, 2015. 
[34] R. Lourenzutti and R. A. Krohling, "A study of TODIM in a intuitionistic fuzzy and random environment," Expert Systems with Applications, vol. 40, no. 16, pp. 6459-6468, 2013.

[35] R. A. Krohling, A. G. C. Pacheco, and A. L. T. Siviero, "IF-TODIM: an intuitionistic fuzzy TODIM to multi-criteria decision making," Knowledge-Based Systems, vol. 53, pp. 142146, 2013.

[36] R. A. Krohling and A. G. C. Pacheco, "Interval-valued intuitionistic fuzzy TODIM," Procedia Computer Science, vol. 31, pp. 236244, 2014.

[37] X. Zhang and Z. Xu, "The TODIM analysis approach based on novel measured functions under hesitant fuzzy environment," Knowledge-Based Systems, vol. 61, pp. 48-58, 2014.

[38] T. Tanino, "Fuzzy preference orderings in group decision making," Fuzzy Sets and Systems. An International Journal in Information Science and Engineering, vol. 12, no. 2, pp. 117-131, 1984.

[39] H. Liao, Z. Xu, and M. Xia, "Multiplicative consistency of hesitant fuzzy preference relation and its application in group decision making," International Journal of Information Technology and Decision Making, vol. 13, no. 1, pp. 47-76, 2014.

[40] Z. Zhang and C. Wu, "Interval-valued hesitant multiplicative preference relations and their application to multi-criteria decision making," British Journal of Mathematics and Computer Science, vol. 4, no. 10, pp. 1390-1426, 2014.

[41] D. Yu, "A scientometrics review on aggregation operator research," Scientometrics, vol. 105, no. 1, pp. 115-133, 2015.

[42] D. J. Yu, Z. S. Xu, Y. Kao, and C. T. Lin, “The structure and citation landscape of IEEE Transactions on Fuzzy Systems (1994-2015)," IEEE Transactions on Fuzzy Systems, 2017.

[43] D. J. Yu, Z. S. Xu, W. Pedrycz, and W. R. Wang, "Information Sciences 1968-2016: a retrospective analysis with text mining and bibliometric," Information Sciences.

[44] X. R. He, Y. Y. Wu, D. J. Yu, and J. M. Merigó, "Exploring the ordered weighted averaging operator knowledge domain: a bibliometric analysis," International Journal of Intelligent Systems.

[45] D. Yu, "Group decision making under multiplicative hesitant fuzzy environment," International Journal of Fuzzy Systems, vol. 16, no. 2, pp. 233-241, 2014.

[46] Y. Jiang, Z. Xu, and X. Yu, "Compatibility measures and consensus models for group decision making with intuitionistic multiplicative preference relations," Applied Soft Computing Journal, vol. 13, no. 4, pp. 2075-2086, 2013.

[47] Z. S. Xu and M. Xia, "Distance and similarity measures for hesitant fuzzy sets," Information Sciences, vol. 181, no. 11, pp. 2128-2138, 2011.

[48] D. Yu, "Intuitionistic fuzzy information aggregation under confidence levels," Applied Soft Computing Journal, vol. 19, pp. 147-160, 2014.

[49] D. Yu and S. Shi, "Researching the development of Atanassov intuitionistic fuzzy set: using a citation network analysis," Applied Soft Computing Journal, vol. 32, pp. 189-198, 2015.

[50] S. Ghosh, T. Chakraborty, S. Saha, M. Majumder, and M. Pal, "Development of the location suitability index for wave energy production by ANN and MCDM techniques," Renewable and Sustainable Energy Reviews, vol. 59, pp. 1017-1028, 2016.

[51] K.-Y. Shen, S.-K. Hu, and G.-H. Tzeng, "Financial modeling and improvement planning for the life insurance industry by using a rough knowledge based hybrid MCDM model," Information Sciences, vol. 375, pp. 296-313, 2017.
[52] D. Yu, "Prioritized information fusion method for triangular intuitionistic fuzzy set and its application to teaching quality evaluation," International Journal of Intelligent Systems, vol. 28, no. 5, pp. 411-435, 2013.

[53] D.-J. Yu and D.-F. Li, "Dual hesitant fuzzy multi-criteria decision making and its application to teaching quality assessment," Journal of Intelligent and Fuzzy Systems, vol. 27, no. 4, pp. 16791688, 2014.

[54] D. Yu, W. Zhang, and Y. Xu, "Group decision making under hesitant fuzzy environment with applications to personnel evaluation," Knowledge-Based Systems, vol. 52, pp. 1-10, 2013.

[55] D. Yu, "Softmax function based intuitionistic fuzzy multicriteria decision making and applications," Operational Research, vol. 16, no. 2, pp. 327-348, 2016.

[56] D. Yu and H. Liao, "Visualization and quantitative research on intuitionistic fuzzy studies," Journal of Intelligent and Fuzzy Systems, vol. 30, no. 6, pp. 3653-3663, 2016.

[57] W. Zhou and Z. Xu, "Optimal discrete fitting aggregation approach with hesitant fuzzy information," Knowledge-Based Systems, vol. 78, no. 1, pp. 22-33, 2015.

[58] D. J. Yu, "Intuitionistic fuzzy geometric Heronian mean aggregation operators," Applied Soft Computing Journal, vol. 13, no. 2, pp. 1235-1246, 2013.

[59] D. J. Yu, J. M. Merig, Y. Xu, and J. M. Merigó, “Group decision making in information systems security assessment using dual hesitant fuzzy set," in Proceedings of the International Journal of Intelligent Systems, vol. 31, pp. 786-812, 2016.

[60] W. Zhou, Z. Xu, and M. Chen, "Preference relations based on hesitant-intuitionistic fuzzy information and their application in group decision making," Computers and Industrial Engineering, vol. 87, article no. 4018, pp. 163-175, 2015.

[61] D. F. Li, “TOPSIS-based nonlinear-programming methodology for multiattribute decision making with interval-valued intuitionistic fuzzy sets," IEEE Transactions on Fuzzy Systems, vol. 18, no. 2, pp. 299-311, 2010.

[62] D. F. Li, "A ratio ranking method of triangular intuitionistic fuzzy numbers and its application to MADM problems," Computers \& Mathematics with Applications, vol. 60, no. 6, pp. 15571570, 2010.

[63] D. Yu, "Multiattribute decision making based on intuitionistic fuzzy interaction average operators: a comparison," International Transactions in Operational Research, vol. 22, no. 6, pp. 1017-1032, 2015.

[64] D. Yu, J. M. Merigó, and L. Zhou, "Interval-valued multiplicative intuitionistic fuzzy preference relations," International Journal of Fuzzy Systems, vol. 15, no. 4, pp. 412-422, 2013.

[65] D. Li and J. Yang, "Fuzzy linear programming technique for multiattribute group decision making in fuzzy environments," Information Sciences, vol. 158, pp. 263-275, 2004.

[66] D. J. Yu, "Archimedean aggregation operators based on dual hesitant fuzzy set and their application to GDM," International Journal of Uncertainty, Fuzziness and Knowledge-Based Systems, vol. 23, no. 5, pp. 761-780, 2015.

[67] Y. Zheng, B. Jeon, D. Xu, Q. M. Wu, and H. Zhang, "Image segmentation by generalized hierarchical fuzzy C-means algorithm," Journal of Intelligent and Fuzzy Systems, vol. 28, no. 2, pp. 961-973, 2015.

[68] D. Yu, "Some hesitant fuzzy information aggregation operators based on einstein operational laws," International Journal of Intelligent Systems, vol. 29, no. 4, pp. 320-340, 2014. 
[69] D. Yu, "Group decision making based on generalized intuitionistic fuzzy prioritized geometric operator," International Journal of Intelligent Systems, vol. 27, no. 7, pp. 635-661, 2012.

[70] J. M. Merigó and M. Casanovas, "Decision-making with distance measures and induced aggregation operators," Computers and Industrial Engineering, vol. 60, no. 1, pp. 66-76, 2011.

[71] S. Zhang and D. Yu, "Some geometric Choquet aggregation operators using Einstein operations under intuitionistic fuzzy environment," Journal of Intelligent and Fuzzy Systems, vol. 26, no. 1, pp. 491-500, 2014.

[72] J. M. Merigó and A. M. Gil-Lafuente, "The induced generalized OWA operator," Information Sciences, vol. 179, no. 6, pp. 729741, 2009.

[73] D. Yu, "Some generalized dual hesistant fuzzy geometric aggregation operators and applications," International Journal of Uncertainty, Fuzziness and Knowledge-Based Systems, vol. 22, no. 3, pp. 367-384, 2014.

[74] M. M. Xia, Research on fuzzy decision information aggregation techniques and measures [Ph.D dissertation], Southeast University, Jiangsu Sheng, China, 2012.

[75] L. Suganthi, S. Iniyan, and A. A. Samuel, "Applications of fuzzy logic in renewable energy systems-A review," Renewable and Sustainable Energy Reviews, vol. 48, pp. 585-607, 2015.

[76] H. Bagci and A. Yazici, "An energy aware fuzzy approach to unequal clustering in wireless sensor networks," Applied Soft Computing Journal, vol. 13, no. 4, pp. 1741-1749, 2013.

[77] D. J. Yu and C. Xu, "Mapping research on carbon emissions trading: a co-citation analysis," Renewable and Sustainable Energy Reviews, vol. 74, pp. 1314-1322, 2017.

[78] M. Gong, L. Su, M. Jia, and W. Chen, "Fuzzy clustering with a modified MRF energy function for change detection in synthetic aperture radar images," IEEE Transactions on Fuzzy Systems, vol. 22, no. 1, pp. 98-109, 2014.

[79] H. Gupta and M. K. Barua, "Supplier selection among SMEs on the basis of their green innovation ability using BWM and fuzzy TOPSIS," Journal of Cleaner Production, vol. 152, pp. 242-258, 2017.

[80] J. K. Roehrich, S. U. Hoejmose, and V. Overland, "Driving green supply chain management performance through supplier selection and value internalisation: a self-determination theory perspective," International Journal of Operations and Production Management, vol. 37, no. 4, pp. 489-509, 2017.

[81] C. Bohner and S. Minner, "Supplier selection under failure risk, quantity and business volume discounts," Computers and Industrial Engineering, vol. 104, pp. 145-155, 2017. 


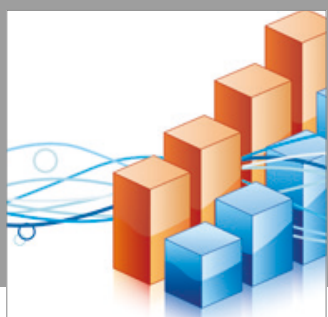

Advances in

Operations Research

vatersals

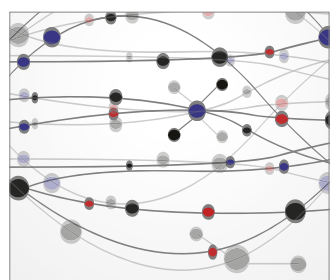

\section{The Scientific} World Journal
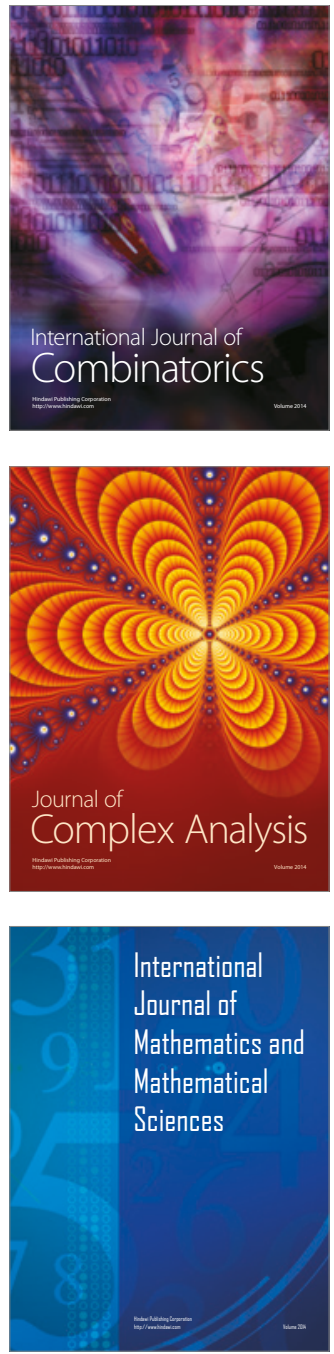
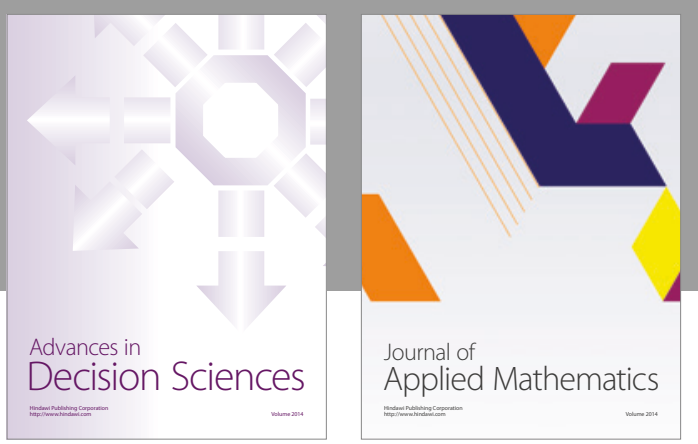

Algebra

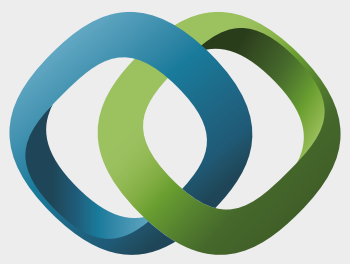

\section{Hindawi}

Submit your manuscripts at

https://www.hindawi.com
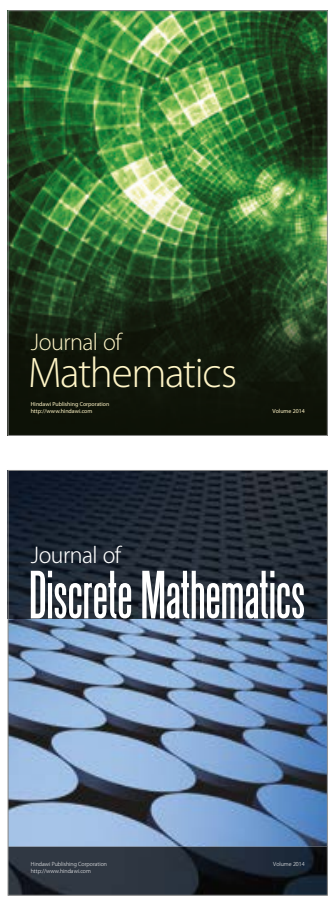

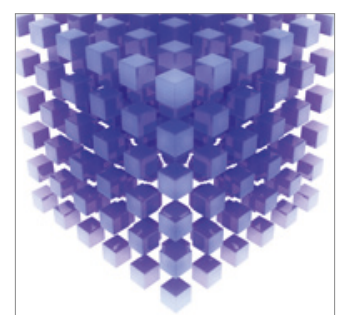

Mathematical Problems in Engineering
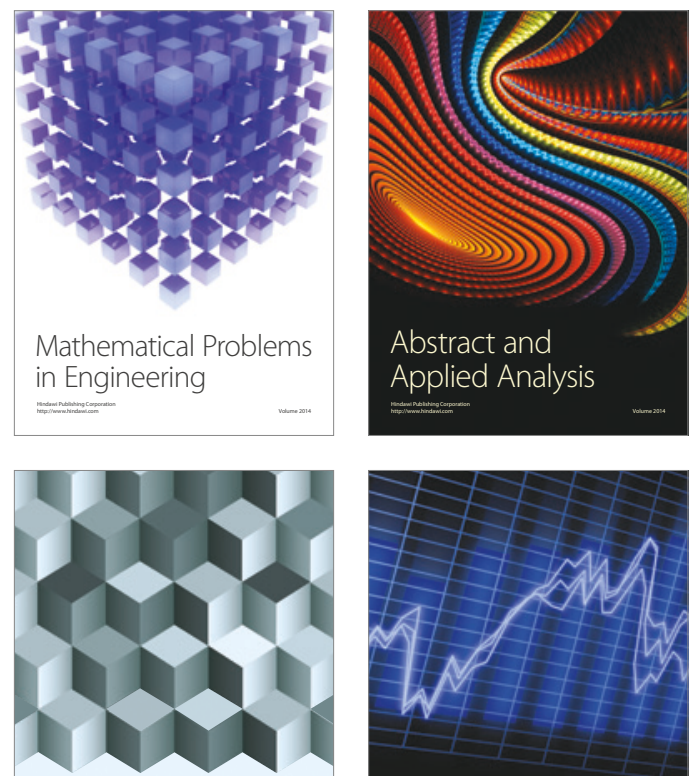

Journal of

Function Spaces

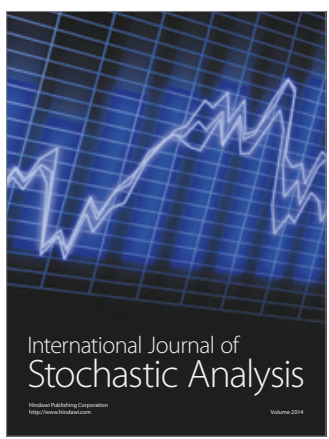

Probability and Statistics
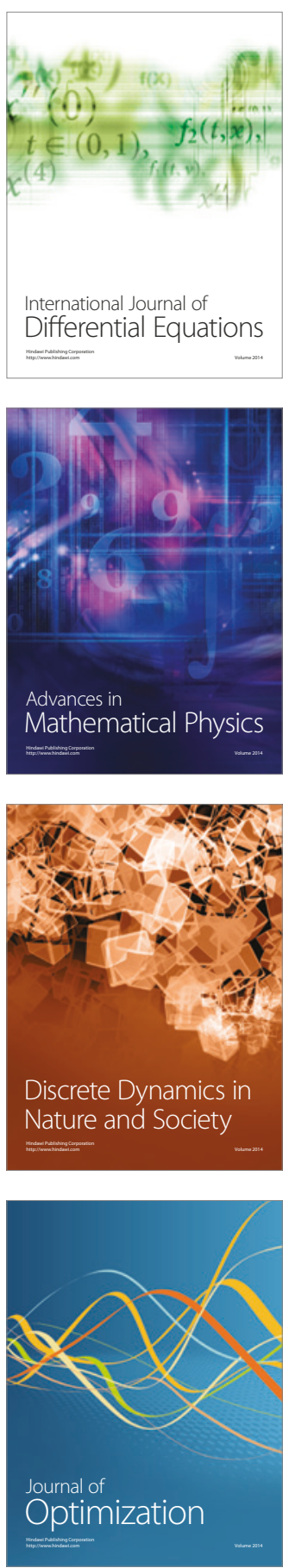